REVIEW

\title{
Proposals to Conduct Randomized Controlled Trials Without Informed Consent: a Narrative Review
}

\author{
James H. Flory, MD, MSCE, Alvin I. Mushlin, MD, SCM, and Zachary I. Goodman, BA
}

Department of Healthcare Policy and Research, Weill Cornell Medical College, New York, NY, USA.

BACKGROUND: Individual informed consent from all participants is required for most randomized clinical trials (RCTs). However, some exceptions-for example, emergency research-are widely accepted.

METHODS: The literature on various approaches to randomization without consent (RWOC) has never been systematically reviewed. Our goal was to provide a survey and narrative synthesis of published proposals for RWOC. We focused on proposals to randomize at least some participants in a study without first obtaining consent to randomization. This definition included studies that omitted informed consent entirely, omitted informed consent for selected patients (e.g., the control group), obtained informed consent to research but not to randomization, or only obtained informed consent to randomization after random assignment had already occurred. It omitted oral and staged consent processes that still obtain consent to randomization from all participants before randomization occurs.

RESULTS: We identified ten different proposals for RWOC: two variants of cluster randomization, two variants of the Zelen design, consent to postponed information, two-stage randomized consent, cohort multiple RCT, emergency research, prompted optional randomization trials, and low-risk pragmatic RCTs without consent.

CONCLUSION: Of all designs discussed here, only cluster randomized designs and emergency research are routinely used, with the justification that informed consent is infeasible in those settings. Other designs have raised concerns that they do not appropriately respect patient autonomy. Recent proposals have emphasized the importance for RWOC of demonstrating such respect through systematic patient engagement, transparency, and accountability, potentially in the context of learning health care systems.

KEY WORDS: Informed consent; Randomized controlled trials; Bioethics; Clinical research; Learning health care system.

J Gen Intern Med 31(12): 1511-8

DOI: $10.1007 /$ s11606-016-3780-5

(C) Society of General Internal Medicine 2016

\section{INTRODUCTION}

Randomized controlled trials (RCTs) are the gold standard for clinical research. ${ }^{1}$ Informed consent, including disclosure of randomization, is an ethical requirement for most RCTs. ${ }^{2}$ This

Received April 25, 2016

Revised June 6, 2016

Accepted June 8, 2016

Published online July 6, 2016 principle, intended to protect participants' autonomy and dignity, is firmly embedded in guidelines and regulations. ${ }^{3-6}$ But, critics have argued that modern consent processes often fail to convey information well, can confuse or distress participants, and may even hinder legitimate research endeavors to the point where patients are paradoxically harmed by the lack of research on the safety and effectiveness of commonly used therapies. ${ }^{7,8}$

These arguments have led to calls to relax or eliminate informed consent requirements in certain circumstances. An example is the exception for emergency medicine studies in which it is deemed impossible to obtain informed consent and still test an emergent intervention. ${ }^{9}$ More broadly, US Federal regulations allow a waiver of informed consent requirements for clinical research given that four requirements are met: (1) "the research involves no more than minimal risk to the subjects," (2) "the waiver or alteration will not adversely affect the rights and welfare of the subjects," (3) "the research could not practicably be carried out without the waiver," and (4) "whenever appropriate, the subjects will be provided with additional pertinent information after participation." 3 The interpretation of whether or not a study meets these standards is the responsibility of Institutional Review Boards (IRBs).

The argument continues to be made that more RCTs should be done without informed consent, either through broader application of existing waiver processes or revision of regulations. $^{7,10,11}$ The idea is now raised in the specific context of learning health care systems, which are expected to conduct rigorous comparative effectiveness research at a scale and pace that some authors have argued is essential for patient wellbeing but unrealistic with current informed consent requirements. ${ }^{7}$ However, it is unclear how often, or in what context, randomization without consent (RWOC) occurs.

RWOC is just one way to address concerns with current informed consent requirements. A literature also exists on efforts to "streamline" informed consent by shortening consent forms or replacing them with an oral process or to "stage" it in multiple sessions over time. These innovations may improve recruitment, trust, and comprehension by preventing patients from being overwhelmed with excessive detail. ${ }^{12-14}$ RWOC is distinct from these proposals in that it contradicts the intuitive ethical principal that patients should be told that they are participating in an experiment before the experiment begins. In doing so, it raises unique ethical issues while opening the door to more radical changes, such as not obtaining consent at all. 
We undertook a narrative review with the goal of providing evidence and conceptual frameworks for future research and policy regarding RWOC. This review describes published research designs that eliminate or attenuate informed consent to the point where randomization is not disclosed to at least some research participants.

\section{SEARCHING THE LITERATURE}

Traditional electronic searches of ethics literature are challenging because of difficulty defining standard search terms for ethical concepts. ${ }^{15}$ Further, the diverse RWOC proposals could not be synthesized in a fully quantitative or objective fashion. For these reasons, we pursued a narrative rather than systematic review. However, a systematic literature search was undertaken and provided the starting point for the narrative review.

In the systematic search, the PubMed database was queried using "randomized controlled trials as topic [MESH term] AND informed consent [MESH term]" in the date range January 1, 1970 to September 1, 2015. Inclusion criteria were a description of a research design that would not require informed consent prior to randomization from all participants. This definition included studies that omitted informed consent entirely, omitted informed consent for selected patients (e.g., the control group), obtained informed consent to research but not to randomization, or only obtained informed consent to randomization after random assignment had already occurred. It omitted oral and staged consent processes that still obtain consent to randomization from all participants before randomization occurs.

On recognition of some recurring design elements in diverse proposals, the authors collaboratively and inductively divided the proposals into categories to organize the data presentation.

\section{REVIEW OF KNOWN PROPOSALS FOR RANDOMIZATION WITHOUT INFORMED CONSENT}

The PubMed search identified 20 eligible manuscripts that described 10 distinct approaches to RWOC. Numerous RCTs conducted without informed consent have been published that did not appear in this literature search. However, all of those known to the authors could be classified under one of the ten proposals identified by the formal literature search.

The designs are detailed in Tables 1, 2, and 3 and in Figure 1. They are described below, organized by common design themes.

\section{Designs Based on Infeasibility of Informed Consent}

One of the most widely used RWOC types is emergency research. For this, an otherwise typical RCT design is used, but informed consent is not obtained because patients are too sick and the medical situation too urgent to obtain informed consent before a time-sensitive intervention must be carried out. The resulting impossibility of obtaining informed consent has been widely accepted as justifying a waiver of informed consent, provided the research is of sufficient importance. The design is explicitly permitted by federal regulations and is in routine use. ${ }^{9}$ A recent example compared two induction agents for emergent bronchial intubation. ${ }^{16}$

Cluster randomized studies are the other common case of RWOC. Sim and Dawson offer a detailed discussion, in which they further divide the category into cluster-cluster and individual-cluster research. ${ }^{17}$ Both of these are in routine use.

In cluster-cluster designs, the intervention is delivered at a community level, making it practically impossible for each individual patient to refuse it. While community members could provide consent in some such circumstances, it would be 'inert,' because all community members would be exposed to the intervention whether they consent or not. If the intervention can only be practically implemented at the community level, the infeasibility of individual consent is used to justify this design. One example is a cluster-randomized study of dengue prevention, which randomly assigned villages to interventions, such as destruction of mosquito breeding grounds, that would affect all village residents regardless of whether they consented individually. ${ }^{19}$

In an individual-cluster design, the intervention is assigned at the community level, but delivered at the individual level. An example is a study of interventions to reduce neonatal mortality. ${ }^{18}$ The intervention, which consisted primarily of education on newborn care, was randomly assigned to whole villages at a time, but in principle individuals could opt out of receiving it. Sim and Dawson argue that omission of informed consent in such cases is justifiable if consent would be "incompatible with the methodological integrity of the study," a determination that they suggest should be made by IRBs on a case-by-case basis. They note that using a cluster design must be methodologically necessary and "should not be used merely as a means of avoiding inconvenient ethical requirements such as gaining informed consent."

\section{Designs That Omit Informed Consent for Control Groups}

A second family of proposals for RWOC are based on the idea that it may not be necessary to obtain informed consent from patients who are randomized to a control arm that receives the usual standard of care. This idea was first articulated in the late 1970 s, in the context of oncology studies where an experimental treatment is compared to the best available standard of care. ${ }^{8}$ Many study designs in this family are referred to as 'randomized consent,' although to avoid ambiguity we avoid the term here.

In the original proposal (Zelen single-consent), patients were randomized prior to any consent, and informed consent to experimental treatment was sought only from individuals who were assigned to experimental treatment. The design was 
Table 1 Designs based on the infeasibility of informed consent

\begin{tabular}{|c|c|c|c|c|}
\hline Design & $\begin{array}{l}\text { Reported } \\
\text { uses }\end{array}$ & Explanation of design & Example of design & $\begin{array}{l}\text { Rationale for omitting informed } \\
\text { consent to randomization }\end{array}$ \\
\hline $\begin{array}{l}\text { Emergency } \\
\text { research }\end{array}$ & $\begin{array}{l}\text { Routinely } \\
\text { used }\end{array}$ & $\begin{array}{l}\text { Studies can be conducted on } \\
\text { emergent interventions without } \\
\text { informed consent }\end{array}$ & $\begin{array}{l}\text { RCT comparing two induction } \\
\text { agents for patients undergoing } \\
\text { urgent or emergent endotracheal } \\
\text { intubation }\end{array}$ & $\begin{array}{l}\text { There would be no other means of } \\
\text { conducting this research, and the } \\
\text { research is considered important for } \\
\text { public health }\end{array}$ \\
\hline $\begin{array}{l}\text { Individual-cluster } \\
\text { cluster } \\
\text { randomization }\end{array}$ & $\begin{array}{l}\text { Routinely } \\
\text { used }\end{array}$ & $\begin{array}{l}\text { A randomized intervention occurs } \\
\text { at the individual level, but effect is } \\
\text { studied at the community, or } \\
\text { cluster level }\end{array}$ & $\begin{array}{l}\text { Site-randomized trial of } \\
\text { behavior change intervention } \\
\text { reducing neonatal mortality }\end{array}$ & $\begin{array}{l}\text { While possible, individual consent } \\
\text { would be "deemed incompatible with } \\
\text { the methodological integrity of the } \\
\text { study" }\end{array}$ \\
\hline $\begin{array}{l}\text { Cluster-cluster } \\
\text { cluster } \\
\text { randomization }{ }^{17}\end{array}$ & $\begin{array}{l}\text { Routinely } \\
\text { used }\end{array}$ & $\begin{array}{l}\text { A randomized intervention, such } \\
\text { as an environmental management } \\
\text { trial, occurs at the community } \\
\text { level and is also studied at that } \\
\text { level }\end{array}$ & $\begin{array}{l}\text { Site-randomized trial of an } \\
\text { integrated community-based } \\
\text { environmental management } \\
\text { strategy to prevent dengue fe- } \\
\text { ver }{ }^{19}\end{array}$ & $\begin{array}{l}\text { Individual consent is clearly } \\
\text { infeasible: "On both logical and } \\
\text { logistical grounds, individual } \\
\text { informed consent is difficult if not } \\
\text { impossible in a cluster-cluster ran- } \\
\text { domized trial"" }\end{array}$ \\
\hline
\end{tabular}

only proposed for studies in which control patients would receive the same care they would receive if they were never enrolled in a study. Zelen argued that the process of obtaining consent for such control patients could cause unnecessary distress when patients were told about a promising experimental treatment that they would not receive. He asserted that this distress could also compromise the physician-patient relationship and impair recruitment.

Although the Zelen design is often associated with oncology trials, examples exist in other therapeutic areas: for

Table 2 Variations on the Zelen Design

\begin{tabular}{|c|c|c|c|c|}
\hline Design & $\begin{array}{l}\text { Reported } \\
\text { uses }\end{array}$ & Explanation of design & Example of design & $\begin{array}{l}\text { Rationale for omitting informed } \\
\text { consent to randomization }\end{array}$ \\
\hline
\end{tabular}

(Zelen) single- $\quad>10 \quad$ Eligible participants are pre-
randomized con$\operatorname{sent}^{8}$ randomized into treatment groups. Consent is obtained only from those receiving an experimental treatment

(Zelen) double$>10$ randomized con$\operatorname{sent}^{21}$

Two-stage randomized consent (aka nested consent $)^{23}$ Informed consent is obtained for a follow-up study, but randomization is not disclosed. Consent is then obtained from participants randomized to receive non-standard care

Eligible participants are prerandomized into treatment groups. Informed consent is then obtained from all participants for the treatment to which they were assigned, but randomization is not necessarily disclosed

$$
\text { (nested consent) }
$$

Cohort multiple
$\mathrm{RCT}^{24}$

Consent to
postponed postponed ${ }_{\text {information }}^{27}$
An observational cohort is enrolled without consent to specific study randomization. For each RCT, some members of the cohort are randomly selected and offered the trial intervention ${ }^{25}$

Randomization is not disclosed at initial consent. Participants are told that some information is being withheld until the study concludes. Randomization is disclosed after the study
Multicenter randomized trial of the addition of rifampin to combination therapy for Pseudomonas bacteremia. Consent was sought only from patients randomized to the experimental therapy ${ }^{20}$

Randomized trial of short versus long duration of residential drug abuse treatment. This design was used to prevent study dropout among participants who wanted a different program duration than they were randomized to ${ }^{22}$ A smoking cessation program for first-visit patients who answered in a questionnaire survey that they were smokers ${ }^{23}$

A study assessed the clinical and cost-effectiveness of treatment by a homeopath for women with menopausal hot flushes ${ }^{26}$

A study of an outreach nursing care program after stroke hospitalization $^{27}$
Consent is omitted only for patients who are receiving standard of care Preserves the physician-patient relationship:

"The physician need not leave himself open, in the eyes of the patient, to not knowing what he or she is doing and 'tossing a coin'" Spares patients distress: "On the patient's side, there is also an important advantage: before providing consent the patient knows what treatment will be given"

Spares patients distress: "the proposal of a trial with the randomized process and the detailed explanation process exhausts patients, and the explanation may cause a psychologically difficult situation."

Consent is omitted only for patients who are receiving standard of care Spares patients distress: "Patients should not be told about treatment that they might not then receive, nor should they be told that their treatment will be allocated by chance"

Consent is omitted only for patients who are receiving standard of care

Conventional consent would compromise the methodologic integrity of the study, for example, because of dissatisfaction in the control group

Spares patients the distress of hearing about a promising intervention they then do not receive Consent is postponed only for patients who are receiving standard of care 
Table 3 Pragmatic RCT designs that omit informed consent entirely

\begin{tabular}{|c|c|c|c|c|}
\hline$\overline{\text { Design }}$ & $\begin{array}{l}\text { Reported } \\
\text { uses }\end{array}$ & Explanation of design & $\begin{array}{l}\text { Example of } \\
\text { design }\end{array}$ & $\begin{array}{l}\text { Rationale for omitting informed consent } \\
\text { to randomization }\end{array}$ \\
\hline $\begin{array}{l}\text { PORT (Prompted } \\
\text { Optional } \\
\text { Randomization Trial) }\end{array}$ & 0 & $\begin{array}{l}\text { Physicians are prompted to choose particular } \\
\text { drugs based on computerized randomization, } \\
\text { but may easily override those prompts if they } \\
\text { or their patient prefer another treatment. No } \\
\text { informed consent is obtained }\end{array}$ & $\mathrm{N} / \mathrm{A}$ & $\begin{array}{l}\text { Both treatments are standard of care } \\
\text { If patient or provider has a preference, the } \\
\text { prompt will be overridden }\end{array}$ \\
\hline $\begin{array}{l}\text { Low-risk pragmatic } \\
\text { RCT }^{10,29}\end{array}$ & $0 *$ & $\begin{array}{l}\text { Patients are randomly assigned to one of two } \\
\text { low-risk standard of care interventions. No } \\
\text { informed consent is obtained }\end{array}$ & N/A & $\begin{array}{l}\text { Both treatments are standard of care, with no } \\
\text { reason to prefer one over the other } \\
\text { Oversight at the level of a learning health } \\
\text { care system with systematic patient } \\
\text { engagemetn could ensure trial is transparent } \\
\text { and acceptable to patients as a group }\end{array}$ \\
\hline
\end{tabular}

*At least two published studies arguably fit under this category, but do not explicitly cite this design ${ }^{30,31}$

example, patients with pseudomonas bacteremia were randomized to receive rifampin in addition to standard antibiotic therapy, and only those randomized to rifampin were asked for consent. $^{20}$ A systematic review found that the Zelen singleconsent design had been used 23 times by 2006, although revision of the federal regulations in the early 1980s made it more difficult to approve research designs that failed to inform all participants that they were part of an experiment. ${ }^{21,32}$

As a result, the Zelen double-consent design was developed. ${ }^{21}$ In this variant, all participants give informed consent to be in a study, but not to randomization, which is completed before potential participants are approached. The fact that randomization is part of the study is not disclosed until after randomization has occurred and is not necessarily ever disclosed to all participants. The rationale continues to be that this design may improve study recruitment while sparing patients emotional distress. But, descriptions of this proposal also continue to raise questions about whether it is ethical for participants to undergo randomization without their knowledge or consent. Systematic review found that Zelen double-consent designs had been implemented at least 27 times, ${ }^{32}$ often to compare an oncologic treatment to observation or usual care.

Nested consent is a newer variant of the Zelen design in which investigators obtain permission from all patients to follow them prospectively, without any mention of experimental care; a random subset of this cohort is then selected to receive an experimental intervention, and consent for the intervention is obtained from that group. The resulting process is described by the authors as a Zelen single-consent design preceded by a universal consent to follow-up, but not to randomization. ${ }^{23}$ The authors report a single use of the nested consent design to study a smoking cessation program.

The cohort multiple RCT (cmRCT) is similar to nested consent, with two differences. First, it is intended to enable multiple RCTs to be done over time within the same cohort. Second, cmRCT proposals can be implemented with varying levels of informed consent: for example, the initial consent may or may not include an explicit consent to future randomizations. ${ }^{24}$ If such an explicit consent for randomization is not obtained, the design is similar to nested consent. If an explicit up-front consent to randomization is obtained, the cmRCT is not technically RWOC, in that it does inform all participants that randomization will occur. ${ }^{33}$

At least 16 studies have used the cmRCT design. ${ }^{25}$ An early example involved a cohort of women who had consented to participate in a prospective observational study of menopausal symptoms. A subset were randomly selected to be offered a homeopathic intervention for hot flushes. The women who were offered the intervention were asked for informed consent; the other women in the observational cohort served as controls without being informed of the existence of the randomized trial. ${ }^{26}$

Finally, in consent to postponed information, a consent process is carried out during which patients are told that significant information about the study will be withheld until after the study is completed. One such piece of information is the process of randomization. ${ }^{27}$ One of the advantages cited is avoiding distress to patients from discussion of randomization and an intervention they may not receive. Another rationale, and precondition, is that the information disclosure during conventional consent would have to create methodological problems. In the cited example, regular care was compared to increased home visits post-stroke, and the concern was that a conventional consent would result in increased bias, because patients would be disappointed to be randomized to the control arm and would report lower satisfaction.

\section{Designs That Omit Informed Consent Entirely}

Two designs (low-risk pragmatic RCT and PORTs) omit informed consent entirely.

Truog's original proposal was that an otherwise typical lowrisk RCT design could be conducted without any informed consent when two standard-of-care alternatives are being compared under conditions of clinical equipoise. The requirement for equipoise in this case means that "no reasonable person should have a preference for one treatment over any other." The rationale is that patients suffer no incremental risk or harm and all stand to benefit in the long run from the comparative effectiveness data generated. The major objection is that, despite the absence of physical harm, patient autonomy is not respected by this design. ${ }^{29}$

In a more recent publication by Faden and colleagues, Truog's concept is expanded, with a description of how a 

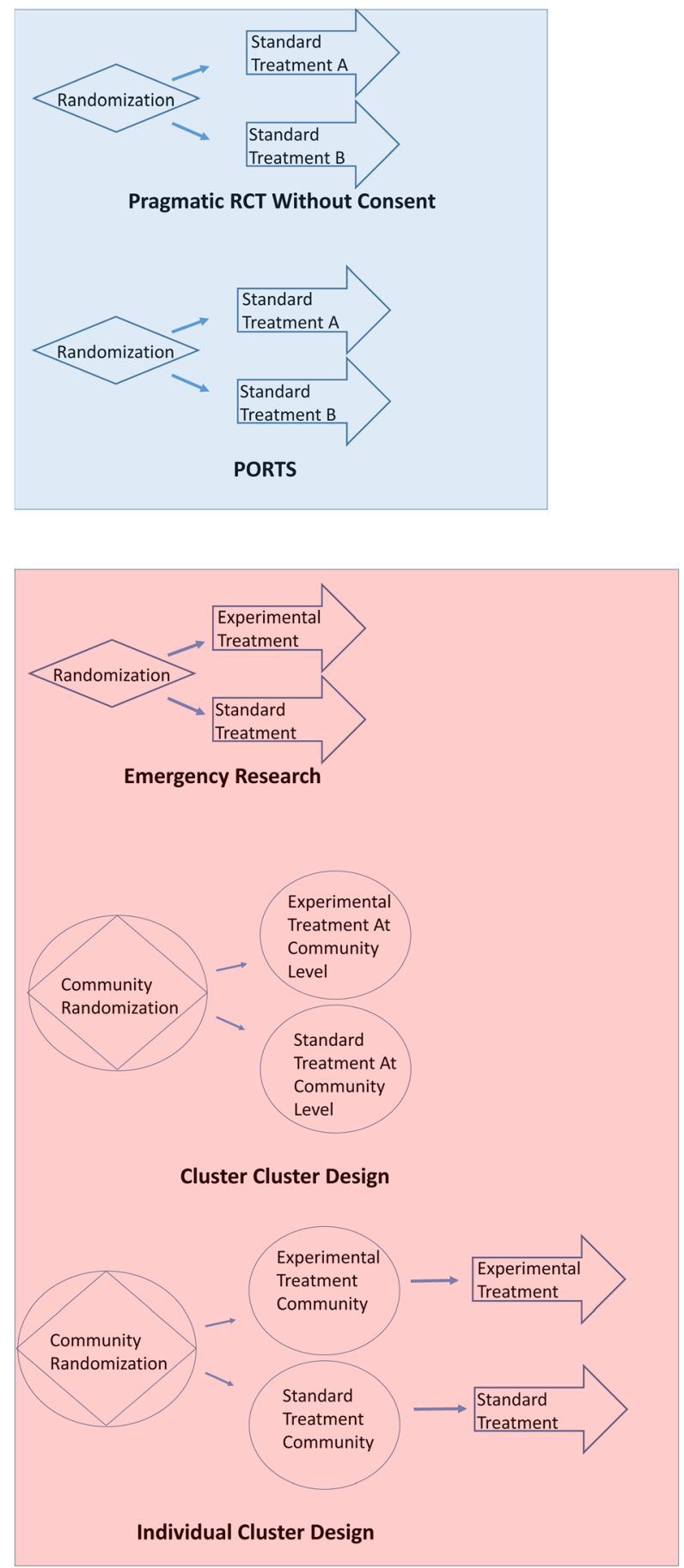
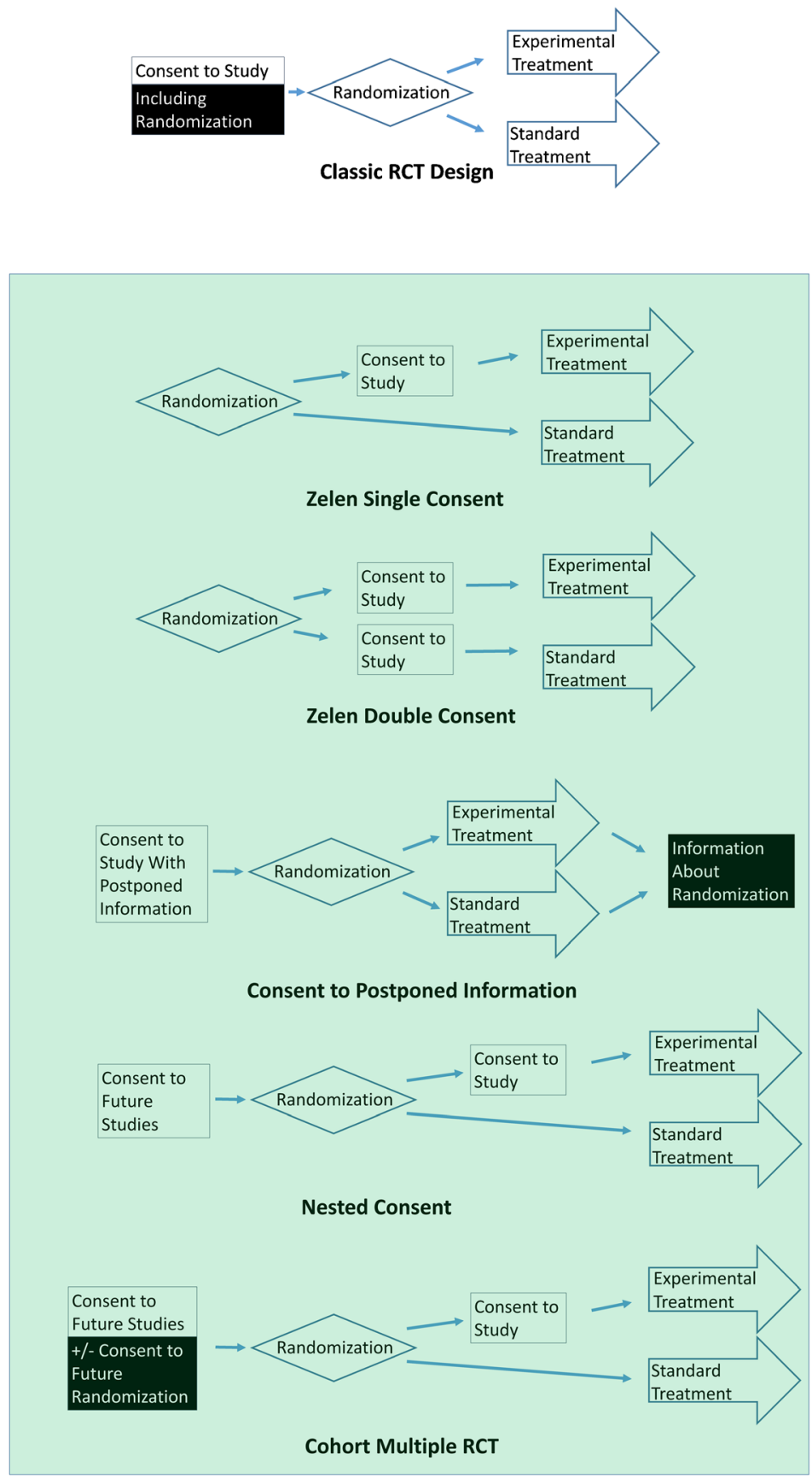

Figure 1 Schematic depiction of proposals to randomize prior to obtaining informed consent to randomization from all participants. Rectangles represent consent; shaded rectangles represent discussion specifically of randomization. Circles represent events occurring at a community rather than individual level. Diamonds represent randomization. Large arrows represent application of an intervention to an individual

low-risk pragmatic RCT can be embedded within a learning health care system that involves patient advocates in the study approval process, advertises that these types of RWOC are taking place, and potentially obtains a pre-consent for study participation (similar to that described in cmRCT) from patients. These additions were intended to protect patient dignity and autonomy to a greater degree than Truog's original proposal would. ${ }^{10}$
We are aware of two low-risk randomized controlled trials in which informed consent was omitted entirely. The first was of feedback to physicians on test ordering behavior; in this case, the rationale for omitting informed consent was not clearly stated, and potential antecedent proposals such as Truog's were not cited. ${ }^{30}$ The second was of intercessory prayer; in this case an IRB waiver was granted because of the classification of the study as having no known risk, no 
additional burden from data collection, and the potential for informed consent process to cause anxiety. ${ }^{31}$ After discussion among the co-authors, both of these designs were classified as examples of a low-risk pragmatic RCT without consent (as more explicitly described in the Truog and Faden proposals).

The Prompted Optional Randomization Trial (PORT) is explicitly related to Truog's proposal and has similar ethical justifications and disadvantages, but has never been implemented. The major difference between PORT and a low-risk pragmatic RCT is that randomization does not directly affect treatment assignment, but instead results in a computerized order entry system prompt to encourage physicians to prescribe one drug versus another. This prompt is designed to be easily overridden if the physician or patient has any preference. This feature is intended to guarantee clinical equipoise and further reduce the possibility of harm to patients, but may reduce study power and generalizability. ${ }^{28}$

\section{DISCUSSION}

This review identified ten distinct proposals for RWOC. Emergency research and cluster randomization have been widely accepted. No other RWOC proposals have been widely adopted, despite arguments that they do not place patients at risk of physical harm. One major barrier is the concern that failing to obtain a feasible informed consent to randomization is disrespectful to patient autonomy even if participation in the trial is safe. ${ }^{34,35}$ Concepts of patient engagement and learning health care systems appear to play a significant role in current efforts to develop RWOC designs that adequately protect patient autonomy. ${ }^{10,36}$

The argument that RWOC is ethical in emergency research and cluster randomized trials is based on the infeasibility of obtaining informed consent. One reason that these designs have been generally accepted is that RWOC is a necessary part of the methodology, not an option chosen because it is most convenient for the investigators. When obtaining informed consent is clearly feasible, however inconvenient or expensive, other arguments for RWOC have been put forward.

Two influential rationales for RWOC were first framed by Zelen. The first is that if patients are not placed at any material risk by participation in a trial, informed consent may be an unnecessary barrier to recruitment. The second is that the informed consent process can directly harm some patients by causing emotional distress and damaging the physician-patient relationship, particularly for patients who are randomized to a non-preferred arm. The demoralization that may occur if patients strongly prefer one treatment and are randomized to the other is both a significant potential harm and a potential source of bias if demoralized patients are less adherent to assigned treatment. ${ }^{37}$

Designs based on these rationales, notably the Zelen double-consent design, remain in use but are not widely accepted. It is unclear to what extent this is due to unexpectedly poor recruitment in practice ${ }^{34}$ or to unresolved ethical concerns.

Most other RWOC designs have drawn on the same basic arguments that, given its disadvantages, informed consent can be omitted when the material risks of study participation are very low. Kim and Miller have counter-argued that patient autonomy is nonetheless violated by RWOC. ${ }^{35}$ This line of objection is particularly credible because the primary purpose of informed consent is to protect patient autonomy. ${ }^{2}$ As an alternative, they suggest that a brief oral consent might be used, making enrollment more feasible but continuing to inform patients of randomization.

An emerging body of empirical literature supports this concern. Both smaller focus group studies and larger scale empirical surveys have found that a plurality of participants prefer to give informed consent to research, including low-risk pragmatic RCTs and even observational studies. ${ }^{38-41}$ In a case where most participants initially rejected RWOC, they were more accepting of a streamlined consent. ${ }^{39}$

Such public preferences may not be fixed: the same study noted a significant increase in participants' willingness to accept an RWOC approach after a period of deliberation on the topic. ${ }^{39}$ The finding that almost all participants wanted to be asked for informed consent even for retrospective research further highlights the challenges in reconciling public opinion with policy. Nonetheless, these results suggest that RWOC designs cannot simply consider the material risk to patients but must also address a widespread desire for individuals to be informed and give consent. In addition, RWOC may need to be justified relative not just to current standards, but also to alternatives like oral consent.

Faden and colleagues have argued that objections to RWOC can best be addressed in the context of a learning health care system, characterized by extensive patient engagement, transparency, and accountability, making it possible to ensure that RWOC, if implemented, would not result in "important affronts to patient dignity." 10 The requirement that RWOC be done only in a learning health care system is an important stipulation. A learning health care system must meet a demanding list of criteria - encompassing engagement, transparency, accountability, use of electronic health records, and much more - that few if any existing health care systems fulfill. ${ }^{42}$

Early experience with cmRCT illustrates the importance of learning health care system concepts. The initial proposal did not emphasize learning health care systems, patient engagement, or transparency. ${ }^{24}$ However, implementations of cmRCT beyond the initial pilot have been marked by engagement with patient stakeholders and collection of quantitative data about patient preferences. ${ }^{36}$ Concurrently, and in response to criticism, the design has been modified to include additional stages of consent (including pre-consent to randomization to future unspecified studies) for the express purpose of enhancing patient engagement and making patients "scientific citizens" within a learning health care system. ${ }^{33}$ This kind of 
engagement, transparency, and responsiveness to critiques has not decisively addressed ethical concerns about $\mathrm{cmRCT},{ }^{43}$ but may help to explain the strikingly rapid acceptance of cmRCT, with a reported 16 studies in 5 years. ${ }^{25}$

Most proposals for RWOC give relatively little attention to how well a proposal complies with existing regulations. This vagueness is understandable: not only do regulations vary by country, but how regulations are interpreted undoubtedly varies among institutional review boards (IRBs). For example, the investigators in an early cmRCT study noted that they felt they could more easily gain ethics approval because a clinician with experience in Zelen designs was on their ethics review board. ${ }^{26}$ Even proposals to omit informed consent entirely for low-risk pragmatic clinical trials might be capable of moving forward under current US regulations, provided the IRB with jurisdiction felt that they met the conditions for waiver of informed consent; however, routinely obtaining such waivers might be difficult without encouragement from a high level in the federal regulatory system. ${ }^{10}$

This review has limitations. By design, it focuses on RWOC rather than encompassing the full range of important innovation, like streamlining, in informed consent. It was impossible to extract data in a fully objective or quantitative way, necessitating narrative review rather than systematic review or meta-analysis. Finally, eligible proposals may have been missed by the literature search strategies used.

In conclusion, substantial ingenuity has been spent devising ethical approaches to RWOC. RWOC is well established in cases where informed consent is infeasible. However, a long line of efforts to implement RWOC more widely have been unable to address concerns about disrespect to patient autonomy and dignity. There is considerable interest in the use of systematic patient engagement in the setting of learning health care systems to help address these concerns. Deeper ethical and empirical analysis of how well such engagement can take the place of traditional informed consent, perhaps informed by ongoing experience with cmRCT, would be a valuable next step.

Acknowledgments: JHF is supported by AHRQ training grant KO8 HSO23898-01. This grant placed no restrictions on the study's design or reporting. None of the authors have conflicts of interest to report.

Corresponding Author: James H. Flory, MD, MSCE; Department of Healthcare Policy and ResearchWeill Cornell Medical College, 425 East 61st Street, 301, New York, NY 10065, USA (e-mail: jaf9052@med.cornell.edu).

\section{REFERENCES}

1. Concato J, Shah N, Horwitz RI. Randomized, controlled trials, observational studies, and the hierarchy of research designs. N Engl J Med. 2000;342(25): 1887-92.

2. Emanuel EJ, Wendler D, Grady C. What makes clinical research ethical? JAMA. 2000;283(20):2701-11.

3. US Department of Health and Human Services: Title 45 (Code of Federal Regulations), Part 46. Protection of Human Subjects. Washington, DC, US Department of Health and Human Services, 2009
4. The Nuremberg code. JAMA. 1996;276:1691.

5. World Medical Association. Declaration of Helsinki. JAMA. 1997;277:925926.

6. National Commission for the Protection of Human Subjects of Biomedical and Behavioral Research. The Belmont Report. Washington, DC:US Government Printing Office; 1979.

7. Faden RR, Beauchamp TL, Kass NE. Informed consent, comparative effectiveness, and learning health care. N Engl J Med. 2014;370(8):766-8.

8. Zelen M. A new design for randomized clinical trials. N Engl J Med. 1979;300(22):1242-1245.

9. US Department of Health and Human Services and Food and Drug Administration: Guidance for Institutional Review Boards, Clinical Investigators, and Sponsors: Exception From Informed Consent Requirements for Emergency Research. Rockville, MD, US Food and Drug Administration, 2013. Available at: http://www.fda.gov/downloads/regulatoryinformation/guidances/ucm249673.pdf. Accessed June 9, 2016.

10. Faden R, et al. Ethics and informed consent for comparative effectiveness research with prospective electronic clinical data. Med Care. 2013;51(8 Suppl 3):S53-57.

11. Platt R, Kass NE, McGraw D. Ethics, regulation, and comparative effectiveness research: time for a change. JAMA. 2014;311(15):1497-8.

12. McKinney RE Jr, Beskow LM, Ford DE, Lantos JD, McCall J, PatrickLake B, Pletcher MJ, Rath B, Schmidt H, Weinfurt K. Use of altered informed consent in pragmatic clinical research. Clin Trials. 2015; 12(5):494-502.

13. Epstein LC, Lasagna L. Obtaining informed consent. Form Substance Arch Intern Med. 1969;123(6):682-8.

14. Angiolillo AL, Simon C, Kodish E, Lange B, Noll RB, Ruccione K, Matloub Y. Staged informed consent for a randomized clinical trial in childhood leukemia: impact on the consent process. Pediatr Blood Cancer. 2004;42(5):433-7.

15. McDougall R. Systematic reviews in bioethics: types, challenges, and value. J Med Philos. 2014;39(1):89-97.

16. Smischney NJ, et al. Ketamine/propofol admixture (ketofol) at induction in the critically ill against etomidate (KEEP PACE trial): study protocol for a randomized controlled trial. Trials. 2015;16(1):177.

17. Sim J, Dawson A. Informed consent and cluster-randomized trials. Am J Public Health. 2012;102(3):480-5.

18. Kumar V, et al. Effect of community-based behaviour change management on neonatal mortality in Shivgarh, Uttar Pradesh, India: a clusterrandomised controlled trial. Lancet. 2008;372(9644):1151-1162.

19. Vanlerberghe $\mathbf{V}$, et al. Community involvement in dengue vector control: cluster randomised trial. BMJ. 2009;338:b1959.

20. Korvick JA, Peacock JE Jr, Muder RR, Wheeler RR, Yu VL. Addition of rifampin to combination antibiotic therapy for Pseudomonas aeruginosa bacteremia: prospective trial using the Zelen protocol. Antimicrob Agents Chemother. 1992;36(3):620-5.

21. Zelen M. Randomized consent designs for clinical trials: an update. Stat Med. 1990;9(6):645-656.

22. McCusker $\mathbf{J}$, et al. The effects of planned duration of residential drug abuse treatment on recovery and HIV risk behavior. Am J Public Health. 1997;87(10): 1637-1644.

23. Hamajima $\mathbf{N}$, et al. Nested consent design for clinical trials. Jpn J Clin Oncol. 1998;28(5):329-332.

24. Relton C, et al. Rethinking pragmatic randomised controlled trials: introducing the "cohort multiple randomised controlled trial" design. BMJ. 2010;340:c1066.

25. Relton C, Thomas $\mathbf{K}$, Nicholl J, Uher $\mathbf{R}$. Poster Presentation: Review of an innovative approach to practical trials: the "cohort multiple RCT" design". Trials. 2015;16(Suppl 2):114.

26. Relton C, O'Cathain A, Nicholl J. A pilot 'cohort multiple randomized controlled trial' of treatment by a homeopath for women with menopausal hot flushes. Contemp Clin Trials. 2012;33(5):853-9.

27. Boter $\mathbf{H}$, et al. Modified informed consent procedure: consent to postponed information. BMJ. 2003;327(7409):284-285.

28. Flory $\mathbf{J}$, Karlawish $\mathbf{J}$. The prompted optional randomization trial: a new design for comparative effectiveness research. Am J Public Health. 2012;102(12):e8-10.

29. Truog RD, et al. Is informed consent always necessary for randomized, controlled trials? N Engl J Med. 1999;340(10):804-807.

30. Winkens RA, Knottnerus JA, Kester AD, Grol RP, Pop P. Fitting a routine health-care activity into a randomized trial: an experiment possible without informed consent? J Clin Epidemiol. 1997;50(4):435-9.

31. Harris WS, Gowda M, Kolb JW, Strychacz CP, Vacek JL, Jones PG, Forker A, O'Keefe JH, McCallister BD. A randomized, controlled trial of the effects of remote, intercessory prayer on outcomes 
in patients admitted to the coronary care unit. Arch Intern Med. 1999;159(19):2273-8.

32. Schellings R, Kessels AG, ter Riet G, Knottnerus JA, Sturmans F. Randomized consent designs in randomized controlled trials: systematic literature search. Contemp Clin Trials. 2006;27(4):320-32.

33. Young-Afat DA, Verkooijen HM, Van Gils CH, Van der Velden JM, Burbach J, Elias SG, Van Delden J, Relton C, Van Vulpen M, Van der Graaf R. Staged-informed consent in the cohort multiple randomized controlled trial design. Epidemiology. 2016.

34. Velthuis MJ, et al. Alternatives for randomization in lifestyle intervention studies in cancer patients were not better than conventional randomization. J Clin Epidemiol. 2012;65(3):288-292.

35. Kim SY, Miller FG. Informed consent for pragmatic trials-the integrated consent model. N Engl J Med. 2014;370(8):769-772.

36. Richards DA, Ross S, Robens S, Borglin G. The DiReCT study-improving recruitment into clinical trials: a mixed methods study investigating the ethical acceptability, feasibility and recruitment yield of the cohort multiple randomised controlled trials design. Trials. 2014;15:398.

37. Bradley C. Designing medical and educational intervention studies. A review of some alternatives to conventional randomized controlled trials. Diabetes Care. 1993;16(2):509-18.

38. Kelley M, James C, Alessi Kraft S, Korngiebel D, Wijangco I, Rosenthal E, Joffe S, Cho MK, Wilfond B, Lee SS. Patient Perspectives on the
Learning Health System: The Importance of Trust and Shared Decision Making. Am J Bioeth. 2015;15(9):4-17.

39. Kass N, Faden R, Fabi RE, Morain S, Hallez K, Whicher D, Tunis S, Moloney R, Messner D, Pitcavage J. Alternative consent models for comparative effectiveness studies: Views of patients from two institutions. AJOB Empirical Bioethics. 2016;7(2):92-105.

40. Cho MK, Magnus D, Constantine M, Lee SS, Kelley M, Alessi S, Korngiebel D, James C, Kuwana E, Gallagher TH, Diekema D, Capron AM, Joffe S, Wilfond BS. Attitudes toward risk and informed consent for research on medical practices: a cross-sectional survey. Ann Intern Med. 2015;162(10):690-6.

41. Riordan F, Papoutsi C, Reed JE, Marston C, Bell D, Majeed A. Patient and public attitudes towards informed consent models and levels of awareness of Electronic Health Records in the UK. Int J Med Inform. 2015;84(4):237-47.

42. Institute of Medicine. The Learning Healthcare System: Workshop Summary. Olsen L, Aisner D, McGinnis JM, eds. Washington, DC: National Academies Press; 2007. Available at: http://www.iom.edu/Reports/2007/ The-Learning-Healthcare-System-Workshop-Summary.aspx. Accessed June 9, 2016.

43. Hunter D. We could be heroes: ethical issues with the pre-recruitment of research participants. J Med Ethics. 2015;41(7):557-8. 